\title{
Место Воронежской области в производительных силах Центрально-Черноземного экономического района
}

\author{
С.И.Жук凶 \\ Набережночелнинский институт Казанского федерального университета, Российская Федерация \\ (423812, просп. Мира, 68/19, г. Набережные Челны, Республика Татарстан) \\ Поступила в редакиию 29.08.2019 \\ Принята к публикаиии 26.02.2020
}

\begin{abstract}
Аннотация: Цель данной работы заключается в определении места, занимаемого Воронежской областью в производительных силах экономического района. Материалы и методы. Для достижения поставленной цели использовались статистический и аналитический методы исследования. Была использована статистическая информация, представленная в официальных изданиях Федеральной службы государственной статистики, а также расположенная на интернет сайте этого ведомства. Данные Росстата были соответствующим образом систематизированы и проанализированы. Результаты. В результате было выяснено, что Воронежская область обладает самыми развитыми производительными силами, в их количественном аспекте, среди регионов Центрально-Черноземного экономического района. Причем область демонстрирует наилучшую в районе положительную динамику изменения производительных сил. Однако она уступает Белгородской области по эффективному использованию располагаемого производственного и трудового потенциала. Белгородская область лидирует в экономическом районе по валовому региональному продукту, приходящемуся на 1 рубль основных фондов, а также по среднемесячной номинальной заработной плате. Результатом исследования является выявление факта, что именно производительные силы позволяют Воронежской области быть не только одним из лидеров социально-экономического развития района, но и располагаться в верхней части рейтинга регионов страны. При этом можно сделать вывод о недостаточно эффективном использовании производительных сил в области. Уровень благосостояния жителей Воронежской области может быть существенно выше.
\end{abstract}

Ключевые слова: производительные силы, Воронежская область, Центрально-Черноземный экономический район, рабочая сила, основные фонды, валовой региональный продукт.

\section{Place of the Voronezh Region in the Productive Forces of the Central Black Earth Economic Region}

\section{S. I. Zhuk ${ }^{凶}$}

Abstract: The socio-economic development of the country as a whole and its subjects, in particular, is determined by the existing productive forces. The article presents an analysis of the state of the labor force and means of production in the regions of the Central black earth economic region. The purpose of this work is to determine the place occupied by the Voronezh region in the productive forces of the economic region. Statistical and analytical research methods were used to achieve this goal. Statistical information provided in official publications of the Federal state statistics service, as well as on the website of this Agency, was used. Rosstat data were systematized and analyzed accordingly. As a result, it was found that the Voronezh region has the most developed productive forces, in their quantitative aspect, among the regions of the Central black earth economic region. Moreover, the region demonstrates the best positive dynamics of changes in productive forces in the region. However, it is inferior to the Belgorod region in terms of effective use of available

() Жук С.И., 2020

E-mail: $\underline{\text { serg-zhuk@yandex.ru }}$

Контент доступен под лицензией Creative Commons Attribution 4.0 License.

The content is available under Creative Commons Attribution 4.0 License. 
production and labor potential. The Belgorod region is the leader in the economic region in terms of gross regional product per 1 ruble of fixed assets, as well as in terms of the average monthly nominal wage. The result of the study is to identify the fact that it is the productive forces that allow the Voronezh region to be not only one of the leaders of the socio-economic development of the region, but also to be located at the top of the rating of the country's regions. At the same time, it can be concluded that the productive forces in the region are not used effectively enough. The level of welfare of residents of the Voronezh region may be significantly higher.

Key words: productive forces, Voronezh region, Central black earth economic region, labor force, fixed assets, gross regional product.

\section{ВВЕДЕНИЕ}

Экономическое состояние любого субъекта Российской Федерации зависит от степени развития производительных сил, расположенных на его территории. Чем больше численность работников, занятых производительным трудом, чем значительнее величина используемых ими средств производства, тем более высокие значения создаваемого продукта, наблюдаются в регионе и, как следствие, выше доходы жителей.

Определяющее значение производительных сил в процессе повышения благосостояния людей, требует от всех уровней власти выработки и осуществления эффективной социально-экономической политики, направленной на развитие производственной сферы. В настоящее время такой полноценной политики не существует. Развитию производительных сил в стране уделяется недостаточно внимания. Проблема же неравномерного размещения производственных ресурсов среди субъектов Российской Федерации вообще не принято обсуждать. Признается за факт - рынок сам все обустроит наиболее эффективным образом.

Формирование полноценной производственной политики невозможно без знания текущего состояния производительных сил, как с точки зрения количественных параметров, так и с позиции их территориального размещения. В силу данного обстоятельства в настоящее время первостепенное значение приобретает изучение состояния и, что особенно важно, динамики изменения производительных сил в регионах страны.

\section{МАТЕРИАЛЫ И МЕТОДЫ ИССЛЕДОВАНИЯ}

Исследование в статье осуществлялось на примере Воронежской области в сопоставлении с другими субъектами Центрально-Черноземного экономического района (ЦЧР). Для большей наглядности приводилось сравнение с наиболее развитыми регионами страны. При изучении текущего состояния и динамики изменения производительных сил использовались статистические данные по рабочей силе и основным фондам предприятий и организаций, опубликованные в сборниках Росстата. Эти данные подвергались математическому и экономическому анализу.

В 2017 году Институт LegatumInstitute провел анализ 142 стран мира по качеству и уровню жизни населения. Россия, согласно проведенному рейтингу, заняла 90-е место, уступив Молдове (88-е место), Кыргызстану (85-е место), Украине (83-е место), Азербайджану (80-е место), Белоруссии (68-е место), Латвии (47-е место) и Литве (43-е место) [7]. Данная ситуация, по нашему мнению, является следствием недостаточного внимания руководства страны развитию отечественного производства, отсутствия должного внимания проблеме рационального размещения производительных сил на территории страны. У Правительства отсутствует экономическая политика, учитывающая региональную специфику, территориальное районирование, отраслевые особенности.

Исследование состояния производительных сил должно основываться на изучении их структурных составляющих, активно взаимодействующих между собой. Составной частью производительных сил выступают люди, участвующие в производственном процессе - рабочая сила. При этом под рабочей силой понимаются лица в возрасте от 15 до 72 лет, которые в рассматриваемый период считаются занятыми или безработными. [4, с. 182] Элементом производительных сил выступают также средства производства - совокупность вещественных элементов производительных сил. Поэтому в статье мы последовательно рассматриваем ситуацию с рабочей силой, а затем со средствами производства.

А. Смит в своем знаменитом труде написал, что «годичный труд каждого народа представляет собою первоначальный фонд, который доставляет ему все необходимые для существования и удобства жизни продукты...» [6, с. 65]. Из данного утверждения следует - чем больше людей в регионе занято производительным трудом, тем, при прочих равных условиях, больший доход будет в нем наблюдаться, а значит более высокий уровень жиз- 
Численность рабочей силы, тыс. человек (составлена по [4])

[Table 1. Number of employees, thousand people (compiled by [4])]

\begin{tabular}{|c|c|c|c|c|c|c|}
\hline & 01.01 .2014 & 01.01 .2015 & 01.01 .2016 & 01.01 .2017 & 01.01.2018 & $\begin{array}{c}\text { Измене- } \\
\text { ние, \% } \\
\text { [Change, } \\
\% \text { ] }\end{array}$ \\
\hline $\begin{array}{l}\text { Центрально- } \\
\text { Черноземный } \\
\text { экономический район } \\
\text { [Central black earth } \\
\text { economic region] }\end{array}$ & 3685 & 3670 & 3660 & 3676 & 3684 & $-\mathbf{0 , 0 3}$ \\
\hline $\begin{array}{l}\text { Белгородская область } \\
\text { [Belgorod region] }\end{array}$ & 810 & 814 & 806 & 822 & 823 & $+1,6$ \\
\hline $\begin{array}{l}\text { Воронежская область } \\
\text { [Voronezh region] }\end{array}$ & 1154 & 1161 & 1162 & 1165 & 1176 & $+1,9$ \\
\hline $\begin{array}{l}\text { Курская область } \\
\text { [Kursk region] }\end{array}$ & 575 & 571 & 571 & 570 & 571 & $-0,7$ \\
\hline $\begin{array}{l}\text { Липецкая область } \\
\text { [Lipetsk region] }\end{array}$ & 613 & 597 & 595 & 597 & 598 & $-2,4$ \\
\hline $\begin{array}{l}\text { Тамбовская область } \\
\text { [Tambov region] }\end{array}$ & 533 & 527 & 526 & 522 & 516 & $-3,2$ \\
\hline
\end{tabular}

ни населения. Численность рабочей силы в Центрально-Черноземном экономическом районе представлена в таблице 1 .

В ЦЧР за анализируемый период численность людей, занятых производительным трудом, снизилась на 0,03\%. При этом численность рабочей силы Воронежской области возросла на 1,9\% и за весь анализируемый период являлась наибольшей в экономическом районе, составляя на начало 2018 года 31,9\%. На втором месте находится Белгородская область, как по темпам возрастания числа производственных работников, так и по общей их численности. Разница в численности рабочей силы между двумя областями составила $30 \%$.В трех других регионах ЦЧР наблюдалось падение численности рабочей силы. Наиболее значительное сокращение $(-3,2 \%)$ произошло в Тамбовской области.

Однако относительно численности населения доля рабочей силы в Белгородской области (53\%) наибольшая в экономическом районе. Аналогичный показатель Воронежской области - 50\%, Тамбовской $-49 \%$. Сравним, в Москве данная величина составляет $57 \%$, Санкт-Петербурге - $57 \%$, в Московской области $-54 \%$.

Данные таблицы 1 позволяют сделать предположение, что лидерами Центрально-Черноземного экономического района по объему производства должны являлятся в указанном периоде Воронежская и Белгородская области, так как в них наблюдалась наибольшая численность рабочей силы. Соответственно наименьший объем выпускаемой продукции должен быть в Тамбовской области. Верность предположения можно подтвердить, проанализировав данные об объеме валового регионального продукта (ВРП), представленные в таблице 2.

В Центрально-Черноземном экономическом районе наибольший объем производства наблюдался в Воронежской и Белгородской областях, соответственно. При этом ВРП Воронежской области превышал в 2017 году валовой продукт соседнего региона на $9 \%$. Если сравнить это значение с разницей в численности рабочей силы, то можно констатировать наличие в Белгородской области более высокой производительности труда. Наименьшее значение ВРП зафиксировано в Тамбовской области, располагавшей наименьшей численностью рабочей силы.

В том же году ВРП Воронежской области составлял $6 \%, 23 \%$ Московской области и $22 \%$ Ленинградской. Численность же рабочей силы Воронежской области составляла $17 \%$ от Москвы, $29 \%$ от Московской области и $39 \%$ от Ленинградской. Это означает существенное отставание Воронежской области по производительности труда от социально-экономических лидеров регионов РФ. 
Валовой региональный продукт, млн. рублей (составлено по [1])

[Table 2. Gross regional product, million rubles (compiled by [1])]

\begin{tabular}{|c|c|c|c|c|c|c|}
\hline & 01.01 .2014 & 01.01 .2015 & 01.01 .2016 & 01.01 .2017 & 01.01.2018 & $\begin{array}{c}\text { Изме- } \\
\text { нение, } \\
\% \\
\text { [Change, } \\
\%]\end{array}$ \\
\hline $\begin{array}{l}\text { Центрально- } \\
\text { Черноземный } \\
\text { экономический } \\
\text { pайон } \\
\text { [Central blacke arth } \\
\text { economic region] }\end{array}$ & 2004290,6 & 2319753,2 & 2602556,4 & 2690154,1 & 2836981,3 & 41,5 \\
\hline $\begin{array}{l}\text { Белгородская } \\
\text { область } \\
\text { [Belgorod region] }\end{array}$ & 569006,4 & 619677,7 & 693379,4 & 729083,8 & 785646,7 & 38,1 \\
\hline $\begin{array}{l}\text { Воронежская } \\
\text { область } \\
\text { [Voronezh region] }\end{array}$ & 611720,4 & 717667,2 & 805969,6 & 817283,0 & 865222,7 & 41,4 \\
\hline $\begin{array}{l}\text { Курская область } \\
\text { [Kursk region] }\end{array}$ & 271542,5 & 298287,3 & 336999,4 & 362393,8 & 387577,2 & 42,7 \\
\hline $\begin{array}{l}\text { Липецкая область } \\
\text { [Lipetsk region] }\end{array}$ & 315685,4 & 398464,5 & 448994,3 & 483653,3 & 497981,0 & 57,7 \\
\hline $\begin{array}{l}\text { Тамбовская область } \\
\text { [Tambov region] }\end{array}$ & 236335,9 & 285656,5 & 317213,7 & 297740,2 & 300553,7 & 27,2 \\
\hline
\end{tabular}

Для перспектив социально-экономического развития региона важно увеличение валового регионального продукта. По этому критерию оценки состояния производительных сил ЦЧР на первом месте расположилась Липецкая область. Ее ВРП увеличился за 5 лет на 57,7 \%, что превышает среднее значение по району. Наименьший рост регионального продукта $(27,2 \%)$ наблюдался в Тамбовской области.

Положительная динамика изменения ВРП свидетельствует о росте производительности труда во всех субъектах ЦЧР. Однако более точно об эффективности использования рабочей силы в субъектах, о ее влиянии на социально-экономическое развитие, можно судить по доли ВРП на одного работающего - выработке. Валовой региональный продукт, приходящийся на единицу рабочей силы, представлен в таблице 3 .

Воронежская область, лидер Центрально-Черноземного экономического района по общему объему валового регионального продукта, обладала третьим по величине значением ВРП, приходящимся на одного работающего, уступая по этому показателю Белгородской и Липецкой областям.
Отстает область и от Москвы (2188270 рублей на начало 2018 года), от Московской области (932553 рубля) и от Санкт-Петербурга (1271424 рубля). Данное обстоятельство означает недостаточно эффективное использование в Воронежской области имеющейся рабочей силы.

По динамике роста выработки в экономическом районе Воронежская область тоже находится на третьем месте, уступая Липецкой и Курской областям. По этому показателю эффективности производительных сил последнее место занимает Тамбовская область.

Наличие рабочей силы в достаточной численности и производительности не может являться залогом поступательного развития региона. «...история показывает, что целые страны, несмотря на усердие и бережливость их граждан, были осуждены на бедность и нищету» [4, с. 125]. Немаловажным условием социально-экономического развития является наличие достаточного количества средств производства, выступающих в качестве материальной основы производительных сил. О наличии средств производства в регионе можно судить по величине стоимости основных фондов. 
Валовой региональный продукт, приходящийся на единицу рабочей силы, рублей (составлено по [4])

[Table 3. Gross regional product per unit of labor, rubles (compiled by [4])]

\begin{tabular}{|c|c|c|c|c|c|c|}
\hline & 01.01 .2014 & 01.01 .2015 & 01.01 .2016 & 01.01 .2017 & 01.01 .2018 & $\begin{array}{c}\text { Измене- } \\
\text { ние, \% } \\
\text { [Change, } \\
\%]\end{array}$ \\
\hline $\begin{array}{l}\text { Центрально- } \\
\text { Черноземный } \\
\text { экономический район } \\
\text { [Central blacke arth } \\
\text { economic region] }\end{array}$ & 543905 & 632085 & 711081 & 731816 & 770082 & 41,6 \\
\hline $\begin{array}{l}\text { Белгородская область } \\
\text { [Belgorod region] }\end{array}$ & 702477 & 761275 & 860272 & 886963 & 954613 & 35,9 \\
\hline $\begin{array}{l}\text { Воронежская область } \\
\text { [Voronezh region] }\end{array}$ & 530087 & 618146 & 693605 & 701530 & 735734 & 38,8 \\
\hline $\begin{array}{l}\text { Курская область } \\
\text { [Kursk region] }\end{array}$ & 472248 & 522395 & 590192 & 635779 & 678769 & 43,7 \\
\hline $\begin{array}{l}\text { Липецкая область } \\
\text { [Lipetsk region] }\end{array}$ & 514984 & 667445 & 754612 & 810139 & 832744 & 61,7 \\
\hline $\begin{array}{l}\text { Тамбовская область } \\
\text { [Tambov region] }\end{array}$ & 443407 & 542043 & 603068 & 570383 & 582468 & 31,4 \\
\hline
\end{tabular}

Данные о стоимости основных фондов в Центрально-Черноземном экономическом районе приведены в таблице 4.

Наибольшая величина стоимости основных фондов среди субъектов ЦЧР наблюдалась в Воронежской области, за которой, с существенным отставанием, следует Белгородская область. Меньше всего основных фондов было сосредоточено в Тамбовской области. Наблюдаемые различия в стоимости основных фондов характеризуют производственный потенциал регионов. Очевидно, что Воронежская область, располагавшая на начало 2018 года $29 \%$ стоимости основных фондов Центрально-Черноземного района, является лидером по текущим производственным возможностям. Это подтверждает динамика изменения стоимости основных фондов. Так, в Воронежской области наблюдался наибольший прирост стоимости основных фондов в экономическом районе за анализируемый период. Замыкает пятерку Тамбовская область. Очевидно, потенциал развития Воронежской области существенно выше, чем соседней Тамбовской области.

Однако абсолютная величина стоимости основных фондов, сама по себе, не может рассматриваться в качестве решающего фактора социально-экономического развития. Средства производства результативны только при взаимодействии с рабочей силой. Важно единство основных фондов и рабочей силы, как равноправных частей производительных сил региона. Поэтому необходимо выяснить, какой величиной стоимости основных фондов располагает один работающий? Стоимость основных фондов, приходящихся на единицу рабочей силы фондовооруженность, представлена в таблице 5.

Как видно из таблицы 5, по стоимости основных фондов, на единицу рабочей силы лидером Центрально-Черноземного экономического района являлась Липецкая область, за которой следует Белгородская. Воронежская область находится на третьем месте, что означает недополученную продукцию, вследствие отсутствия у рабочей силы максимально возможного количества средств производства. Последнее место занимает Курская область. Стоимость основных фондов на единицу рабочей силы составляет в Москве 5093921 рубль, в Московской области - 1972560 рублей, в СанктПетербурге - 2355766 рублей.

Если же мы рассмотрим динамику фондовооруженности, то лидером экономического района была Воронежская область. Здесь за пять лет стоимость основных фондов, приходящихся на единицу рабочей силы, увеличилась на 56,0\%. Липецкая область с $47,8 \%$ роста находилась на втором месте. Замыкает пятерку в регионе с $40,2 \%$ роста Тамбовская область. 
Стоимость основных фондов, млн. рублей (составлено по [4])

[Table 4. The cost of fixed assets, million rubles (compiled by [4])]

\begin{tabular}{|c|c|c|c|c|c|c|}
\hline & 01.01 .2014 & 01.01 .2015 & 01.01 .2016 & 01.01 .2017 & 01.01 .2018 & $\begin{array}{c}\text { Измене- } \\
\text { ние, \% } \\
\text { [Change, } \\
\% \text { ] }\end{array}$ \\
\hline $\begin{array}{l}\text { Центрально- } \\
\text { Черноземный } \\
\text { экономический район } \\
\text { [Central black earth } \\
\text { economic region] }\end{array}$ & 4302658 & 4756660 & 5202983 & 5717750 & 6334602 & 47,2 \\
\hline $\begin{array}{l}\text { Белгородская область } \\
\text { [Belgorod region] }\end{array}$ & 1035534 & 1152400 & 1289717 & 1400837 & 1501847 & 45,0 \\
\hline $\begin{array}{l}\text { Воронежская область } \\
\text { [Voronezh region] }\end{array}$ & 1158136 & 1233526 & 1401937 & 1534644 & 1841669 & 59,0 \\
\hline $\begin{array}{l}\text { Курская область } \\
\text { [Kursk region] }\end{array}$ & 607109 & 664050 & 705845 & 805024 & 878321 & 44,7 \\
\hline $\begin{array}{l}\text { Липецкая область } \\
\text { [Lipetsk region] }\end{array}$ & 879524 & 997633 & 1066160 & 1178985 & 1268311 & 44,2 \\
\hline $\begin{array}{l}\text { Тамбовская область } \\
\text { [Tambov region] }\end{array}$ & 622355 & 709051 & 739324 & 798260 & 844454 & 35,7 \\
\hline
\end{tabular}

Таблица 5

Стоимость основных фондов, приходящихся на единицу рабочей силы, рублей (составлено по [4])

[Table 5. The cost of fixed assets per unit of labor, rubles (compiled by [4])]

\begin{tabular}{|c|c|c|c|c|c|c|}
\hline & 01.01 .2014 & 01.01 .2015 & 01.01 .2016 & 01.01 .2017 & 01.01 .2018 & $\begin{array}{c}\text { Измене- } \\
\text { ние, \% } \\
\text { [Change, } \\
\% \text { ] }\end{array}$ \\
\hline $\begin{array}{l}\text { Центрально- } \\
\text { Черноземный } \\
\text { экономический район } \\
\text { [Central black earth } \\
\text { economic region] }\end{array}$ & 1167614 & 1296093 & 1421580 & 1555427 & 1719490 & 47,3 \\
\hline $\begin{array}{l}\text { Белгородская область } \\
\text { [Belgorod region] }\end{array}$ & 1278437 & 1415725 & 1600145 & 1704181 & 1824844 & 42,7 \\
\hline $\begin{array}{l}\text { Воронежская область } \\
\text { [Voronezh region] }\end{array}$ & 1003584 & 1062469 & 1206486 & 1317291 & 1566045 & 56,0 \\
\hline $\begin{array}{l}\text { Курская область } \\
\text { [Kursk region] }\end{array}$ & 1055842 & 1162960 & 1236156 & 1412323 & 1538215 & 45,7 \\
\hline $\begin{array}{l}\text { Липецкая область } \\
\text { [Lipetsk region] }\end{array}$ & 1434786 & 1671077 & 1791865 & 1974849 & 2120921 & 47,8 \\
\hline $\begin{array}{l}\text { Тамбовская область } \\
\text { []Tambov region] }\end{array}$ & 1167645 & 1345448 & 1405559 & 1529233 & 1636539 & 40,2 \\
\hline
\end{tabular}

Поскольку основная цель функционирования основных средств - создание товаров и услуг, то важнейшим критерием эффективного их использования может выступать только объем продукции.
Чем больше произведено товаров и оказано услуг в регионе, тем выше его социально-экономическое развитие. Валовой региональный продукт, приходящийся на 1 рубль основных фон- 
Валовой региональный продукт, приходящийся на 1 рубль основных фондов, рублей (составлено по [4])

[Table 6. Gross regional product per 1 ruble of fixed assets, rubles (compiled by [4])]

\begin{tabular}{|l|c|c|c|c|c|}
\hline & 01.01 .2014 & 01.01 .2015 & 01.01 .2016 & 01.01 .2017 & 01.01 .2018 \\
\hline $\begin{array}{l}\text { Центрально- } \\
\text { Черноземный } \\
\text { экономический район } \\
\text { [Central black earth } \\
\text { есопотіс region] }\end{array}$ & $\mathbf{0 , 4 7}$ & $\mathbf{0 , 4 9}$ & $\mathbf{0 , 5 0}$ & $\mathbf{0 , 4 7}$ & $\mathbf{0 , 4 5}$ \\
\hline $\begin{array}{l}\text { Белгородская область } \\
\text { [Веlgorod region] }\end{array}$ & 0,55 & 0,54 & 0,54 & 0,52 & 0,52 \\
\hline $\begin{array}{l}\text { Воронежская область } \\
\text { [Voronezh region] }\end{array}$ & 0,53 & 0,58 & 0,57 & 0,53 & 0,47 \\
\hline $\begin{array}{l}\text { Курская область } \\
\text { [Кursk region] }\end{array}$ & 0,45 & 0,45 & 0,47 & 0,45 & 0,44 \\
\hline $\begin{array}{l}\text { Липецкая область } \\
\text { [Lіреtsk region] }\end{array}$ & 0,36 & 0,40 & 0,42 & 0,41 & 0,39 \\
\hline $\begin{array}{l}\text { Тамбовская область } \\
\text { [Татьов геgion] }\end{array}$ & 0,38 & 0,40 & 0,43 & 0,37 & 0,36 \\
\hline
\end{tabular}

дов - фондоотдача, представлен в таблице 6.

Наиболее высокий показатель ВРП, приходящийся на 1 рубль основных фондов в Центрально-Черноземном экономическом районе, наблюдался в Воронежской области. В среднем за анализируемый период в области на 1 рубль основных фондов приходилось 0,536 рубля ВРП. Это выше, чем в среднем по экономическому району. На втором месте с показателем 0,534 рубля находилась Белгородская область. Самый низкий показатель у Тамбовской области. Валовой региональный продукт, приходящийся на 1 рубль основных фондов Москвы составлял на начало 2018 года 0,39 рубля, Московской области - 0,44 рубля, Санкт-Петербурга - 0,52 рубля. Можно утверждать - Воронежская область обладает достаточно эффективными основными фондами не только в Центрально-Черноземном экономическом районе, но и в стране.

Эффективность производительных сил должна отразиться на социальных показателях региона, в частности, на величине заработной платы. По нашему мнению, чем выше Валовой региональный продукт, приходящийся на единицу рабочей силы (таблица 3), тем, при прочих равных условиях, выше доход рабочей силы. Среднемесячная номинальная начисленная заработная плата в субъектах Центрально-Черноземного экономического района представлена в таблице 7.
Самая высокая заработная плата в ЦЧР у работников Белгородской области. Это обстоятельство свидетельствует о значительно более высоком социальном результате функционирования производительных сил области по сравнению с другими регионами района. Вторая по величине заработная плата наблюдалась в Липецкой области, располагавшая вторым по величине Валовым региональным продуктом, приходящимся на единицу рабочей силы. Воронежская область находится на третьей позиции, немного уступая лидерам. Однако отставание от ведущих субъектов страны более существенное. На начало 2018 года заработная плата в Москве была 73812 рублей, в Московской области - 46836 рублей, в Санкт-Петербурге - 53740 рублей.

\section{ОБСУЖДЕНИЕ РЕЗУЛЬТАТОВ}

Проведенный анализ позволяет утверждать, что среди субъектов Центрально-Черноземного экономического района, в наибольшей степени производительные силы получили развитие в Белгородской и Воронежской областях. Воронежская область, обладая самой большой численностью рабочей силы и крупнейшими основными фондами в экономическом районе, уступает Белгородской области по эффективности их использования и социальной ориентированности. Поэтому не удивительно, что в рейтинге регионов страны за 2017 год Белгородская область расположилась на 
Среднемесячная номинальная начисленная заработная плата, рублей (составлено по [4])

[Table 7. Average monthly nominal accrued salary, rubles (Based on [4])]

\begin{tabular}{|c|c|c|c|c|c|c|}
\hline & 01.01 .2014 & 01.01 .2015 & 01.01 .2016 & 01.01 .2017 & 01.01 .2018 & $\begin{array}{c}\text { Измене- } \\
\text { ние, \% } \\
\text { [Change, } \\
\% \text { ] }\end{array}$ \\
\hline $\begin{array}{l}\text { Центрально- } \\
\text { Черноземный } \\
\text { экономический район } \\
\text { [Central black earth } \\
\text { economic region] }\end{array}$ & 21145 & 22977 & 24106 & 25552 & 27411 & 29,6 \\
\hline $\begin{array}{l}\text { Белгородская область } \\
\text { [Belgorod region] }\end{array}$ & 22221 & 23895 & 25456 & 27091 & 29066 & 30,8 \\
\hline $\begin{array}{l}\text { Воронежская область } \\
\text { [Voronezh region] }\end{array}$ & 21825 & 24001 & 24906 & 26335 & 28007 & 28,3 \\
\hline $\begin{array}{l}\text { Курская область } \\
\text { [Kursk region] }\end{array}$ & 21234 & 23099 & 23921 & 25327 & 27274 & 28,4 \\
\hline $\begin{array}{l}\text { Липецкая область } \\
\text { [Lipetsk region] }\end{array}$ & 21391 & 23133 & 24524 & 26214 & 28455 & 33,0 \\
\hline $\begin{array}{l}\text { Тамбовская область } \\
\text { [Tambov region] }\end{array}$ & 19056 & 20757 & 21725 & 22795 & 24253 & 27,3 \\
\hline
\end{tabular}

13 месте [5]. При этом Воронежская область находилась на 16 позиции. Места других субъектов Центрально-Черноземного экономического района следующие: Липецкая область - 19 позиция, Курская область - 30, а Тамбовская область - 54. Присутствие четырех регионов в первой половине рейтинга означает, что в Центрально-Черноземном экономическом районе развитие производительных сил опережает среднероссийские темпы. Но по некоторым промышленным показателям наши выводы не совпадают с некоторыми воронежскими авторами [2].

\section{ЗАКЛЮЧЕНИЕ}

Данное исследование свидетельствует о неравномерном размещении производительных сил по субъектам Российской Федерации. Существенно различается и эффективность использования производственного потенциала. Все это необходимо учитывать при разработке различных программ социально-экономического развития регионов, а также о необходимости формирования на федеральном уровне политики территориального развития производительных сил страны.

\section{СПИСОК ЛИТЕРАТУРЫ}

1. Валовой региональный продукт по субъектам Российской Федерации. Доступно: $\mathrm{http}: / / \mathrm{mrd} . \mathrm{gks} . \mathrm{ru} / \mathrm{wps} /$ wcm/connect/rosstat_ts/mrd/ru/statistics/grp/ (дата обращения: 28.08.2019)

2. Крупко А.Э., Михно В.Б. Факторы, проблемы, направления устойчивого развития Центрально-Черноземного района // Вестник Воронежского государственного университета. Серия География. Геоэкология, 2019, № 1, с. 55-73.

3. Лист Ф. Национальная система политической экономии. М., Издательство «Европа», 2005. 382 с.

4. Регионы России. Социально-экономические показатели. 2018: Стат. сб. / Росстат. М., 2018. 1162 с.

5. Рейтинг социально-экономического положения регионов - 2018. Доступно: http://riarating.ru/infografika/ 20180523/630091878.html (дата обращения: 29.08.2019)

6. Смит А. Исследование о природе и причинах богатства народов. М., Эксмо, 2007. 960 с.

7. Уровень жизни населения России и стран мира в 2017 году. Доступно: https:// subscribe.ru/group/nazavalinke/14185363/ (дата обращения: 28.08.2019)

\section{REFERENCES}

1. Gross regional product for the subjects of the Russian Federation. (In Russ.) Available: http://mrd.gks.ru/wps/ wcm/connect/rosstat_ts/mrd/ru/statistics/grp/ (accessed: 28.08.2019)

2. Krupko A.E., Mikhno V.B. Faktory, problemy, napravleniya ustoychivogo razvitiya Tsentral'no-Chernozemnogo rayona [The factors, problems and main directions of sustainable development of the Central Black Soil Region]. Vestnik Voronegskogo gosudarstvennogo univer- 
siteta. Seriya Geografiya, Geoekologiya, 2019, no. 1, pp. 55-73. (In Russ.)

3. List F. National system of political economy. Moscow, Publishing House "Europe", 2005. 382 p. (In Russ.)

4. Region of Russia. Socio-economic indicators. Moscow, Rosstat, 2018. 1162 p. (In Russ.)

5. Rating of socio-economic situation of the regions 2018. (In Russ.) Available: http://riarating.ru/infografika/ 20180523/630091878.html (accessed: 29.08.2019)

\section{КОНФЛИКТ ИНТЕРЕСОВ}

Автор декларирует отсутствие явных и потенциальных конфликтов интересов, связанных с публикацией настоящей статьи.

\section{Жук Сергей Иванович}

кандидат экономических наук, доцент, Набережночелнинского института Казанского федерального университета, г. Набережные Челны, Республика Татарстан, Российская Федерация, ORCID: https://orcid.org/0000-0003-3786-9781, E-mail: $\underline{\text { serg-zhuk@yandex.ru }}$
6. Smith A. Research about the nature and causes of the wealth of Nations. Moscow, Eksmo, 2007. 960 p. (In Russ.)

7. The standard of living of the population of Russia and the world in 2017. (In Russ.) Available: https:// subscribe.ru/group/na-zavalinke/14185363/ (accessed: 28.08.2019)

\section{CONFLICT OF INTEREST}

The author declares no information of obvious and potential conflicts of interest related to the publication of this article.

\section{Sergei I. Zhuk}

Cand. Sci. (Econ.), Assoc. Prof. at the Naberezhnye Chelny Institute of Kazan Federal University, Naberezhnye Chelny, Republic of Tatarstan, Russian Federation, ORCID: https://orcid.org/0000-0003-3786-9781, E-mail: serg-zhuk@yandex.ru 